\title{
A HOSPITAL BASED STUDY ON LIPID PROFILE IN SMOKERS AND NON SMOKERS- A COMPARATIVE STUDY
}

\author{
Afroz Afshan, Manjushree Sugoor, I. Amruta Swati, Revansiddappa B Patil
}

1. Assistant Professor, Department of Physiology, Konaseema Institute of Medical Sciences, Amalapuram.

2. Assistant Professor, Department of Biochemistry, KBNIMS, Gulbarga.

3. Associate Professor, Department of Community Medicine, KBNIMS, Gulbarga.

4. Associate Professor, Department of Physiology, M. R Medical College, Gulbarga.

\section{CORRESPONDING AUTHOR}

Dr. Afroz Afshan.

Sofi residence,

H. No 5-993-246/A. Near New Children Park, Mecca Colony

Ring Road, Gulbarga-585104 (Karnataka)

E-mail: drafrozafshan@gmail.com,

Ph: 00919019319222.

ABSTRACT: BACKGROUND: Smoking is one of the environmental factors which can alter normal lipid profile. It is one of the major risk factors in the genesis of coronary atherosclerosis and development of coronary heart disease. AIMS: To evaluate and compare the lipid profile in both groups and to evaluate the existence of dose dependent relationship and durational significance between smoking and lipid profile among smokers. SETTINGS AND DESIGN: Out of 100 apparently healthy male subjects of age group 21-40yrs, 50 were smokers and 50 were non smokers. All the subjects were non alcoholic, non -obese, normotensives and from same socioeconomic status. Subjects who smoke more than equal 10 cigarettes for more than 2 years were considered as smokers group. METHODS AND MATERIAL: The subjects were asked to fast overnight and early morning blood samples collected and analyzed for lipid profile by appropriate methods. STATISTICAL ANALYSIS USED: The student's unpaired " $\mathrm{t}$ " test was used for statistical analysis. P-value of $<0.05$ or P value $<0.01$ was considered statistically significant. RESULTS: In our study we found serum TC, TG, LDL and VLDL were higher in smokers as compared to non smokers and the serum HDL level was significantly decreased in smokers compared to non smokers showing greater risk of these persons to atherosclerosis and coronary heart disease.

Conclusions: - We conclude our study with the observation that smoking causes alteration in lipid profile. Increased amount and duration of smoking causes more dyslipidaemia .This alteration in serum lipid levels increases risk for coronary artery disease.

KEY WORDS: Cigarette Smoking, Coronary Heart Disease, Dyslipidaemia, Lipid profile and Tobacco.

INTRODUCTION: Smoking is generally considered to be associated with increased risk of a variety of medical disorders. Diet and environmental factors influence the lipid profile. Smoking is one of the environmental factors which can alter normal lipid profile and several studies provide the evidence that tobacco is strongly associated with altering the normal status of the lipid profile. Tobacco smoking is one of the largest single preventable causes of ill health in the world. ${ }^{1}$ People smoke for many reasons like for relieving stress, for enjoyment, social reinforcement etc. Usually smoking starts with a curiosity to know how it feels at a tender age of 
12-14 years. Kessler ${ }^{2}$ defined smoking as a "Pediatric Disease". The prevalence of smoking has reached its peak among teenagers.

Teenagers are not aware of harmful effects of smoking. Smoking parents, attractive smoking and tobacco chewing advertisements, unhealthy bets on maximum smoking challenges, inadequate legislation to control smoking have made the teenage smokers to become adult chronic smokers. All these factors have contributed tobacco smoking as a major factor of preventable cardiovascular and respiratory morbidity and mortality. Relationship of Coronary Heart Disease (CHD) and smoking was first developed by White et al. ${ }^{3}$ and Doll et al. ${ }^{4}$ Incidence of developing CHD is directly related to the number of cigarettes smoked. Sudden death is 2-4 times more in heavy smokers than in non smokers. ${ }^{5}$ It has been suggested that cigarettes when consumed more than 10 per day on regular constitute a major risk factor for CHD. ${ }^{6}$

This study was carried out to assess the impact of active tobacco smoking on lipid profile and to compare the effect of smoking in apparently healthy adult male smokers and nonsmokers.

\section{AIMS:}

1. To evaluate and compare the lipid profile in both smokers and non-smokers.

2. To evaluate the existence of dose dependent relationship and durational significance between smoking and lipid profile among smokers.

MATERIALS AND METHODS: This study was conducted in the Department of Physiology and Biochemistry, M.R.M.C. and Basaveshwar teaching hospital Gulbarga, after obtaining the permission of the Ethical committee of our institution. The present study includes apparently healthy male subjects in the age group of 21-40 years of Gulbarga city. All the subjects gave the informed consent. The inclusion criteria of study subjects includes Non Smokers [control group, $\mathrm{n}=50$ ] non alcoholic, non smokers, non-obese and Smokers group [ $\mathrm{n}=50]$, subjects who smoke more than 10 cigarettes for more than 2 years and non-alcoholic subjects. The exclusion criteria of our study includes subjects below $21 \mathrm{yrs}$ and above $40 \mathrm{yrs}$ of age, obese, persons with angina, diabetics, alcoholics, subjects with renal failure, hepatic failure and females excluded from the study as female smokers are almost non-existent in our area. All subjects were of same socioeconomic status. Detailed history, name, age, sex, occupation, personal history and personal habits of the subjects were taken. Smoking history was taken in detail. Family history of hypertension, diabetes and obesity were enquired. These were noted in a personal Performa and parameters concerned with the study were recorded. The lipid profile parameters include serum Total Cholesterol [TC], Triglycerides [TG], Low Density Lipoproteins [LDL], High Density Lipoproteins [HDL] and Very Low Density Lipoproteins [VLDL].

The subjects were asked to fast overnight and early morning blood sample from the antecubital vein of each subject [5 ml blood] was collected under all aseptic precautions. Samples were processed within 1 hour for quantitative lipoprotein cholesterol measurements using the vertical spin ultracentrifugation technique. Serum was obtained by centrifugation for $4 \mathrm{~min}$ at $3000 \mathrm{rpm}$ and was then transferred into properly labeled sterile vials and stored at $20^{\circ} \mathrm{C}$ till the performance of lipid profile. Serum TC was measured by CHOD-PAP method ${ }^{7}$, serum TG by GPO -TRINDER method ${ }^{8}$ and HDL-C tests by Phosphotungstic Acid method ${ }^{9}$ whereas LDL-C and VLDL-C was determined by calculation method. ${ }^{10}$ All the tests were done on ERBA Chem-7 semi autoanalyser with in 1 hour after collection of sample in biochemistry laboratory at Basaveshwar Teaching and General Hospital.

Journal of Evolution of Medical and Dental Sciences/Volume1/Issue5/November-2012Page-663 
The student's unpaired " $t$ " test was used for statistical analysis. P-value less than 0.05 or $P$ value less than 0.01 was considered statistically significant.

RESULTS: In our study out of 50 smokers and 50 non smokers $44 \%$ were in the age group of 21 to 30 years and $56 \%$ were in the age group of 31 to 40 years. Out of 50 smokers $23(46 \%)$ smokers were smoking 10 cigarettes per day and 27(54\%) smoking more than 10 cigarettes per day. Majority i.e. 32(64\%) of smokers were smoking for more than 5 years duration and $18(36 \%)$ smoking for less than $5 y r s$.

Table 1 depicts the age wise distribution of subjects in both smokers group and non smokers group with mean age distribution of $29.15 \pm 5.91$ and $33.8 \pm 5.15$ years. This table reveals that majority $68 \%$ of smokers were in the age group of 31-40 years.

Table 2 shows the comparison of lipid profile in both smokers group and non smokers group. A significant $(\mathrm{P} \leq 0.005)$ rise of lipid profile i.e. Total Cholesterol, Serum Triglycerides, Low density lipoproteins and Very low density lipoproteins was observed among smokers group than their control group. On the other hand no significant rise of lipid profile was observed among non smokers. HDL was decreased in smokers group compared to non smokers; this decrease was statistically significant with $p$ value $\leq 0.005$.

Table 3 indicates that the number of total cigarettes smoked per day has a significant impact on lipid profile as mean Total cholesterol, Triglycerides, LDL, VLDL were higher in smokers who smoke more than 10 cigarettes per day in comparison to those who smoke 10 cigarettes per day. This observed difference is statistically highly significant with $\mathrm{p}<0.001$ and $<0.005$ respectively for LDL and Total cholesterol. HDL level was lower in subjects who were smoking more than 10 cigarettes per day.

The Table 4 reveals that duration of smoking in years has an impact on lipid profile as Total cholesterol (243mg/dl), Triglycerides (185mg/dl), and LDL $(161 \mathrm{mg} / \mathrm{dl})$ were high among smokers who were smoking for more than 5 years in comparison to smokers of less than 5 years of duration With $\mathrm{P}<0.001,0.01$ and 0.05 respectively.HDL level was significantly lower $33.5 \pm 3$ among smokers smoking for more than 5 years in contrast to those smoking for less than 5 years of duration i.e. HDL $39.7 \pm 2$ with $\mathrm{P}<0.05$.

DISCUSSION AND CONCLUSION: Tobacco smoke contains many constituents; nicotine is one of the main constituents. Nicotine and other toxic substances from tobacco smoke are absorbed through the lungs into the blood stream and are circulated throughout the body. These substances narrow or damage the blood vessel walls; hence plaques form at a faster rate in smokers.11 There is definite relationship between tobacco use and atherosclerosis. Therefore even modest cigarette smoking during adolescence and early adulthood adversely alters the serum lipid and lipoprotein levels. $(12,13,14)$

We conducted this study to assess the impact of smoking on lipid profile. In our study all subjects in both smokers and non smokers group were apparently healthy adult males who were non-diabetic, non-alcoholic and normotensives. In our study Serum TC, TG, LDL and VLDL were significantly higher in smokers as compared to non-smokers and the serum HDL level was significantly lower in smokers as compared to non-smokers.

Our findings are in accordance with the findings of many research workers. The change in the serum lipoprotein levels became more marked with the number of cigarettes smoked per day and duration of smoking in years. This finding has been substantiated by N S Neki. ${ }^{15}$ Contrary to the above findings Diricana $\mathrm{M}$ et al did not find significant differences in serum $\mathrm{TC}$, 
TG, LDL HDL levels between smokers and nonsmokers. ${ }^{16}$ Nesje LA et al also found no significant difference between smokers and non-smokers concerning triglycerides and total cholesterol. ${ }^{17}$ Dyslipidemia is a well-established risk factor for the development of coronary artery disease. Our study demonstrated presence of dyslipidemia in chronic smokers.

Increased levels of Triglycerides, Total cholesterol, LDL, VLDL and lower HDL in smokers points to coronary artery disease. HDL is an anti-atherogenic substance; its fall raises cardiovascular disease. The rapid reduction of its risk after cessation of smoking implies that tobacco enhances thrombosis and contributes in formation of atherosclerotic plaque. The health benefits of smoking cessation occur faster for cardiovascular diseases compared to other conditions.

We conclude our study with the observation that smoking causes dyslipidemia. Increased amount and duration of smoking also enhances this condition .This dyslipidemic state is an increased risk for coronary artery disease.

As statistical analysis were dependent on the accuracy of self reported smoking habits and age this could limit significance of the result. The result of our study cannot be generalized at this stage to the entire population because of small sample size and local geographical representation.

The policies that prevent and reduce smoking will have immediate and large benefits for reducing cardiovascular mortality. ${ }^{18}$ Creating awareness regarding health consequences of smoking in schools and colleges by establishment of mandatory public health education and other antismoking advice should be made an important part of public health system.

ACKNOWLEDGEMENT: This research paper is made possible by the support from the participants of our study. We dedicate our acknowledgment of gratitude towards Dr. Rashmi. C. G as she kindly read our paper and offered valuable detailed advices on grammar, organization, and theme of the paper. Finally, we sincerely thank almighty, family and friends, who provided financial support and timely advice.

\section{REFERENCES:}

1. (WHO) World Health Organization (1983). Chronicle 37: 86-90.

2. Kessler DA, Natanblut SL, Wilkenfeld JP, Lorraine CC, Mayl SL, Bernstein IBG (1997). Nicotine addiction: a pediatric disease. J. Pediatr. 130: 518-524.

3. White, P.D; Coronary disease \& coronary thrombosis in youth. J.Med. Soc. J. 1935:32: 596605

4. Doll, R, \& Hill, A.B. Mortality in relation to smoking. Br.Med. J. 1964: ii: 399-440.

5. Stanler, J.Wentworth D. Is the relationship between serum cholesterol \& risk of premature death from coronary heart disease continuous \& graded? JAMA 1986: 256:2823-28.

6. Garrison, R.J. Kannel, W.B. Cigarette smoking \& HDL cholesterol. Atherosclerosis: 1979: 30,17 .

7. Roeschalu P Bernt E and Gruber W A Clin Biochem 1974; 12(226).

8. Mc Gowan, M.W etal.Clin.Chem, 1988 ;29:538.

9. Burstein M. Scholnic HR,Morfin R.J Lipid Res,1970.

10. Carl.A.Burtis, Edward Ashwood, Cardiac function teitz Textbook of clinical Biochemistry and molecular Diagnostic; $4^{\text {th }}$ edition; Saunders publications: 1619-1660.

Journal of Evolution of Medical and Dental Sciences/Volume1/Issue5/November-2012Page-665 
11. Mitchell B (1999). Tobacco use and cessation: The adverse health effects of tobacco and Tobacco-Related Products. Primary Care: Clin. Office Pract., 26: 463-498.

12. Glueck CJ, Heiss G, Morrison JA, Khoury P, Moore M (1981). Alcohol intake, cigarette smoking and plasma lipids and lipoproteins in 12-19 year children. Circulation 64: 48-56.

13. Freedman DS, Srinivasan SR, Shear CL, Hunter SM, Croft JB, Webber LS (1986). Cigarette smoking initiation and longitudinal changes in serum lipids and lipoproteins in early adulthood: The Bogalusa Heart Study. Am. J. Epidemiol. 124: 207-219.

14. Craig WY, Palomaki GE, Johnson AM, Haddow JE(1990). Cigarette smoking-associated changes in blood lipid and lipoprotein levels in the 8- to 19-year-old age group: a metaanalysis. Pediatr. 85: 155-158.

15. Neki NS. Lipid profile in chronic smokers-A clinical Study. JIACM; 3:51-4,(2002)

16. Dirican M, Sarandol E , Ulukaya E, Tokullugil HA. Effects of smoking on Serum lipid and lipoproteinconcentrations and lecithin: cholesterolacyltransferase activity. J. Med. Invest. 46:169-172, (1999)

17. Nesje LA, Mjøs OD. Plasma HDL cholesterol and the subclasses HDL2 ISSN 09756299 Vol.1/Issue-4/Oct-Dec.2010 www.ijpbs.net Biochemistry B 113 and HDL3 in smokers and non-smokers .Artery. ; 13 (1):7-18, (1985)

18. Ezzati M, Henley SJ, Thun MJ, Lopez AD, . Role of Smoking in Global and Regional Cardiovascular Mortality. Circulation.; 112: 489-497, (2005).

Table-1: Age distribution of subjects studied

\begin{tabular}{|l|l|l|l|l|}
\hline \multirow{2}{*}{ Age in years } & \multicolumn{2}{l|}{ Non-Smoking group } & \multicolumn{2}{l|}{ Smoking group } \\
\cline { 2 - 5 } & Number & $\%$ & Number & $\%$ \\
\hline $21-30$ & 28 & 56.0 & 16 & 32.0 \\
\hline $31-40$ & 22 & 44.0 & 34 & 68.0 \\
\hline Total & 50 & 100.0 & 50 & 100.0 \\
\hline Mean \pm SD & $29.14 \pm 5.91$ & & $33.80 \pm 5.15$ & \\
\hline
\end{tabular}

Table 2:- Comparison of lipid profile between smokers and non smokers

\begin{tabular}{|l|l|l|l|}
\hline Lipid profile & $\begin{array}{l}\text { Smokers } \\
\mathrm{n}=50 \\
\text { Mean } \pm \mathrm{SD}(\mathrm{mg} / \mathrm{dl})\end{array}$ & $\begin{array}{l}\text { Non }- \text { smokers } \\
\mathrm{n}=50 \\
\text { Mean } \pm \mathrm{SD}(\mathrm{mg} / \mathrm{dl})\end{array}$ & P value \\
\hline Total cholesterol[TC] & $220 \pm 40.3$ & $162 \pm 29.1$ & 0.005 \\
\hline Triglycerides[TG] & $182.4 \pm 41.1$ & $109.1 \pm 25.4$ & 0.005 \\
\hline LDL & $142.3 \pm 32.4$ & $101.4 \pm 20.2$ & 0.005 \\
\hline VLDL & $22.7 \pm 5.6$ & $21.1 \pm 5.4$ & 0.98 \\
\hline HDL & $38.8 \pm 3.9$ & $45.7 \pm 5.8$ & 0.005 \\
\hline
\end{tabular}

Results are presented in Mean \pm SD, $P$ value obtained by student $t$ test.

Journal of Evolution of Medical and Dental Sciences/Volume1/Issue5/November-2012Page-666 
Table 3:- lipid profile among smokers based on number of cigarettes smoked per day

\begin{tabular}{|l|l|l|l|}
\hline Lipid profile & $\begin{array}{l}10 \text { cigarettes per day } \\
\mathrm{n}=23 \\
\text { Mean } \pm \mathrm{SD}(\mathrm{mg} / \mathrm{dl})\end{array}$ & $\begin{array}{l}>10 \text { cigarettes per day } \\
\mathrm{n}=27 \\
\text { Mean } \pm \mathrm{SD}(\mathrm{mg} / \mathrm{dl})\end{array}$ & P value \\
\hline Total cholesterol & $191 \pm 30$ & $259 \pm 32$ & 0.005 \\
\hline Triglycerides & $164 \pm 30$ & $183 \pm 50$ & 0.1 \\
\hline LDL & $102 \pm 21$ & $166 \pm 22$ & 0.001 \\
\hline VLDL & $24 \pm 18$ & $26 \pm 16$ & 0.17 \\
\hline HDL & $38 \pm 7$ & $35 \pm 4$ & 0.1 \\
\hline
\end{tabular}

Results are presented in Mean \pm SD, $P$ value obtained by student $t$ test.

Table 4:- lipid profile among smokers based on duration of smoking.

\begin{tabular}{|l|l|l|l|}
\hline Lipid profile & $\begin{array}{l}\text { Duration of smoking } \\
<5 y r s[\mathrm{n}=18] \\
\text { Mean } \pm \mathrm{SD}(\mathrm{mg} / \mathrm{dl})\end{array}$ & $\begin{array}{l}\text { Duration of smoking } \\
>5 \mathrm{yrs}[\mathrm{n}=32] \\
\text { Mean } \pm \mathrm{SD}(\mathrm{mg} / \mathrm{dl})\end{array}$ & P value \\
\hline Total cholesterol & $197 \pm 24$ & $243 \pm 51$ & $<0.001$ \\
\hline Triglycerides & $169 \pm 40$ & $185 \pm 48$ & $<0.01$ \\
\hline LDL & $112 \pm 26$ & $161 \pm 24$ & $<0.05$ \\
\hline VLDL & $25 \pm 13$ & $28 \pm 13$ & 0.132 \\
\hline HDL & $39.7 \pm 2$ & $33.5 \pm 3$ & $<0.05$ \\
\hline
\end{tabular}

Results are presented in Mean \pm SD, $P$ value obtained by student $t$ test. 